\title{
UN EPÍGRAFE CIMARRÓN PARA LA LIBERTAD: MONUMENTALIZACIÓN, SILENCIO Y REPETICIÓN EN EL ARCHIVO DE SAN BASILIO DE PALENQUE
}

\author{
POR \\ LUDMILA FERRARI \\ University of Michigan, Ann Arbor
}

La exposición "del monumento al pensamiento" curada en el Museo Nacional de Colombia en octubre del 2012 consiguió emplazar el Palenque de San Basilio dentro de los muros del museo. A diferencia de previas inscripciones culturales palenqueras en formato expositivo, esta exposición se propuso mostrar el espacio cultural de San Basilio de Palenque como "Manifestación cultural nacional del Patrimonio Intangible de la Humanidad". ${ }^{1}$ Ahora bien, la exhibición del palenque cimarrón en tanto patrimonio de la nación crea una fuerte tensión conceptual totalmente inexplorada por la didáctica culturalista del guión museográfico. Esta tensión surge en la articulación de una serie de convenciones representacionales (darstellen) -la reconstrucción escenográfica de los paisajes culturales, la audio-visualización del testimonio, la selección y disposición de índices identitarios-, con el aparato de representación política (vertreten) activo en la patrimonialización y re-conocimiento de San Basilio de Palenque. ${ }^{2}$ Late aquí,

\footnotetext{
1 "Del monumento al pensamiento: Patrimonio de Colombia para la humanidad" se llevó a cabo de octubre del 2012 a enero del 2013. La muestra propuso un recorrido por los "lugares y las manifestaciones" de Colombia inscritos en las listas de Patrimonio Mundial y Patrimonio de la Humanidad de la UNESCO ("Del monumento al pensamiento"). Antes de esta exposición, San Basilio de Palenque hizo parte de la muestra itinerante "Velorios y santos vivos" (2010-2012) la cual, siguiendo la conceptualización cultural acuñada por Nina de Friedemann, proponía "reivindicar las huellas de africanía" presentes en los rituales funerarios de comunidades Negras, Afrocolombianas, Raizales y Palenqueras del País ("Velorios y santos vivos"). Agradezco la colaboración de Yves Moñino en la disposición de material fotográfico y fuentes historiográficas indispensables para la escritura del ensayo, así como su lúcida y generosa lectura del manuscrito. Asimismo, agradezco los pertinentes e informados comentarios del profesor Gustavo Verdesio sobre la versión final del documento.

2 Es precisamente esta diferencia la que anima el análisis de Spivak en Can the Subaltern Speak. Mantengo los términos originales en alemán ya que es en la obliteración de esta diferencia bajo el significante "representación" que se hace analógica la necesaria discontinuidad entre re-presentación y representación: "within state formation and the law, on the one hand, and in subject-predication, on the other". Es en el cubrimiento de esta diferencia que Spivak identifica el desliz (verbal slippage) que
} 
incuestionada, obviada, la producción de Palenque como vínculo cultural de lo nacional con lo universal, nexo fundamental de las operaciones ideológicas de todo museo nacional, pero que en el caso específico de Palenque, consolida la consignación del "Primer pueblo libre de América" en el archivo histórico del Estado. ${ }^{3}$ De este modo, las implicaciones de la exposición no se limitan a visibilizar un repertorio ejemplar de la cultura palenquera, sino a formalizar la reinscripción del palenque cimarrón en el territorio ideológico de la nación. Por tanto, lo que aquí está en juego no solo es la celebración representacional de la cultura palenquera, sino su incorporación dentro del poder representativo del Estado.

Los textos de divulgación de la exposición, simultáneamente, afirman el dominio soberano del Estado sobre el palenque y animan la incorporación de su bienes culturales en los límites de la comunidad nacional: "La exposición es una invitación a comprender y reconocer el significado cultural que estos bienes y manifestaciones ofrecen, destacados por su valor universal y excepcional, y a explorar sus aportes a nuestra constitución como pueblo y nación" (Comunicado 3). El aparato institucional/identitario de la exposición enmarca el reconocimiento como escenario no ya del intercambio entre dos agentes culturales, sino de la entrega de un legado de las comunidades subalternizadas a la nación: "En conjunto forman una herencia histórica que incita a una reflexión sobre nuestro presente y motivan nuevas maneras de percibir, sentir y comunicarnos con las comunidades portadoras de este patrimonio y con el legado moral que este entrega a la humanidad" (Comunicado 3). Lo aquí se representa como "entrega" no es más que la subsunción de la representatividad palenquera al esquema representacional del Estado. Dado que el 'valor' de rescatar se resume en la transmisión de este legado universal, las "comunidades portadoras", homogeneizadas como sujeto unívoco y complaciente con el proyecto de comunidad nacional/universal, son valoradas en términos transaccionales. Aquí, el mensajero desaparece con la entrega del mensaje: la comunidad negra es producida como sitio vacío sobre el cual se inscribe una gramática de lo nuestro en la expropiación valorativa del otro.

marca la reintroducción de un sujeto individual, coherente y productor de auto-representaciones, a través de un discurso intelectual que se presenta a sí mismo como transparente y desentendido de su ejercicio representativo. En tiempos del capitalismo global, el análisis de los dos usos de "representación" indica cómo la escenificación del mundo como representación, a su vez ponderación del valor como representación del trabajo, disimula la recurrencia a un proxi, un agente representante del poder (24249).

3 La traducción al español de intangible heritage ("patrimonio inmaterial"), no disimula el carácter patriarcal/estatal del archivo (patrinomia). Esta relación entre el poder territorial del Estado y las iniciativas de la UNESCO es claramente identificada por Kirshenblatt-Gimblett en el texto de la convención del 2003: "These developments at the national level are consistent with UNESCO'S efforts to mobilize state actors to take the necessary mesures for the safeguarding of the intangible cultual heritage present in its territory" (UNESCO 55). 
Ad portas del bicentenario de la independencia y en medio de un impasse electoral, el proceso de patrimonialización y monumentalización del palenque libre, su inclusión en el museo y en la herencia oficial de la nación, no deja de provocar, por otra parte, un necesario cuestionamiento acerca de la condición temporal de su consignación histórica. Lo que motiva la explicación del comunicado no solo es cómo incorporar estas comunidades en nuestro pasado, sino remarcar que son el pasado de nuestro presente. Con lo cual, el reconocimiento nacional es simultáneamente el desplazamiento temporal de las comunidades afrocolombianas del tiempo presente. La culturalización y por ende la reificación del espacio cimarrón y la evocación instrumental de una "comunidad portadora" del legado son parte de un aparato de captura y exposición que busca controlar el riesgo de un presente compartido y la noción impropia de comunidad que con este se inauguraría. En este marco expositivo, la patrimonialización opera como profilaxis legal que protege la directa vinculación genealógica de la nación colombiana con sus comunidades subalternizadas, sin comprometer su presente soberano.

En un horizonte amplio de análisis, vemos que la exposición "Del monumento al pensamiento" constituiría una tercera recreación representativa (reenactment) del pacto de subsunción del palenque al Estado. Le precede: el monumento al líder cimarrón y presunto fundador de San Basilio de Palenque, Benkos Biohó ("Monumento a la libertad" 1997); y la entrega de la escultura de San Basilio con la cual se sella la firma de la Entente Cordiale en 1713. Tres instancias de confirmación del pacto representativo vehiculadas por tres prótesis diferentes. El "monumento a la libertad" financiado por el programa de la UNESCO "La ruta del esclavo" y diseñado por Guillermo Vallejo concentra las relaciones entre los palenqueros y el poder estatal en el tiempo, desde el consentimiento jurídico de la libertad palenquera firmado en la Entente Cordiale (1713) hasta su remodelación y transformación en plaza pública por la gobernación de Cartagena en el 2015. De esta manera, el monumento no solo se erige como materialización de la paradoja que anima el reconocimiento institucional de la libertad palenquera: el monumento a la libertá cimarrona es necesariamente el monumento a su expropiación, sino que constituye una prótesis de la política cordial del Estado con el palenque.

Este artículo propone ver la consolidación de Palenque como "El primer pueblo libre de América" como un proceso contradictorio el cual sólo se hace posible a partir de la progresiva inclusión del palenque en la territorialidad y la historia escrita de la nación. A partir de esta hipótesis de trabajo, el ensayo analiza el monumento de Benkos Biojó como materialización aporética y sustrato de una fantasmagoría libertaria producida-y reprimida-por la voluntad representativa del archivo y monumentalización de Palenque. En luz de la lectura derridiana de la pulsión destructiva que "anima" el archivo, se analiza la escritura fallida del nombre del pueblo en la inscripción de su monumento como huella del trabajo des-monumentalizador de la différance.

$111 \frac{\text { Revista Iberoamericana, Vol. LXXXII, Núms. 255-256, Abril-Septiembre 2016, 597-618 }}{\text { ISSN 0034-9631 (Impreso) }}$ 
De acuerdo con la investigación histórica de Nina de Friedemann (Ma'ngombe) y Cristina Navarrete (San Basilio y Cimarrones), la creación de numerosos palenques en el territorio colombiano coincide con el inicio del tráfico de esclavos en Cartagena de Indias. Desde el siglo XVI la imposición del régimen esclavista de la Corona Española tuvo que lidiar con fuga constante de los cimarrones o "huidos" hacia la Matuna, el tupido monte tropical del Caribe colombiano. Durante los siglos XVI y XVII los cimarrones representaban una constante amenaza para los vecinos pudientes de Cartagena. No sólo la presencia de los palenques animaba la idea del escape en los esclavizados mantenidos en cautiverio, sino que los continuos asaltos en los caminos y el incontrolado trueque de armas y monedas propiciado por los cimarrones desestabilizaba la imposición soberana de la Corona Española en los nuevos territorios (Navarrete, Cimarrones 96-98). Si bien la persecución de los cimarrones por los soldados de la gobernación cartagenera fue constante y feroz, los terrenos selváticos de la Matuna y las estrategias de guerra de los cimarrones frustraron la gran mayoría de las expediciones. ${ }^{4}$ No es hasta la firma de la Entente Cordiale en 1713 que el obispo Antonio María Casiani logra "someter" uno de los palenques más bravos de la sabana costeña, el palenque presuntamente capitaneado por Benkos Biojó, que la soberanía del gobierno colonial logra extenderse de la ciudad al monte. ${ }^{5}$ El relato mítico del palenque de Biojó ha interpretado la firma de la Entente Cordiale como la heroica victoria de los palenqueros sobre la legislación colonial, momento fundador de San Basilio de Palenque como "El primer pueblo libre de América".

${ }^{4}$ Las expediciones en busca de cimarrones buscaba por una parte, recuperar la inversión perdida al "reducir los huidos a servidumbre" y por otra parte, destruir los palenques como espacios de resistencia al orden colonial. La economía esclavista de Cartagena se sostenía principalmente del comercio de esclavos y en su explotación doméstica -mas que en el esquema extractivista de la plantación. Por lo tanto, y dada la importancia de Cartagena en el tráfico negrero de Sur América, y siendo los esclavos una de las "mercancías más rentables" del sistema esclavista, los cimarrones y sus palenques comportaban además de un problema político, un importante riesgo económico (Cunin, A flor de piel 102).

5 De acuerdo con el relato histórico-mítico, el actual San Basilio de Palenque fue fundado en 1603 por un grupo de cimarrones comandados por el capitán Benkos Biojó, también conocido como el "Rey de Arcabuco". Este palenque resistió los continuos ataques de la gobernación hasta que accede a firmar la Entente Cordiale en 1713. La leyenda de "El rey de Arcabuco" redactada por el médico cartagenero Camilo Delgado en 1913 fue luego difundida en el palenque por Aquiles Escalante (Moñino, "Dos lenguas" 7). Según Navarrete, Biojó corresponde a un rey africano esclavizado en las costas de Guinea quién organizó uno de los primeros palenques en la sabana costeña colombiana. Los cimarrones comandados por el "rey de Arcabuco" eran temidos por los vecinos cartageneros, no sólo por las inesperadas tomas de caminos, sino porque representaban una posibilidad real de escape para sus propios esclavos. En 1603, luego de los continuados fracasos por someter a servidumbre a Biojó y sus cimarrones, se les concedió licencia para circular por Cartagena y portar armas. El acuerdo fue traicionado por la Corona con el juicio y la condena de horca para Biojó en 1621. 
Al respecto, la investigación histórica de María Cristina Navarrete ha polemizado la festejada difusión del mito libertario palenquero. En primer lugar, Navarrete proponer desligar el palenque de la Matuna capitaneado por Biojó, quien en efecto obtuvo permiso para vestir a "la española", portar espada y movilizarse libremente por Cartagena (Cimarrones 68), de la "constitución legal del poblado de San Basilio" a partir de la reducción del palenque de San Miguel por el obispo Antonio María Casiani en 1713 (Cimarrones 112). Al ser desligados de la constitución mítica de Palenque, los requerimientos legales implementados en la constitución del Palenque de San Basilio abren una vía para la interrogación a la constitución de la libertad palenquera cerrada por la estructura completa del mito. Según la investigación de archivo de Navarrete, el 21 de enero de 1713 - día de la firma de la Entente Cordiale- los cimarrones habitantes del palenque de San Miguel, luego de ser encomendados a San Basilio, recibieron el derecho de tenencia y explotación (tasada) de la tierra, así como pasaportes para ingresar libremente a Cartagena. A cambio, los cimarrones accedieron a comprar la libertad de los veintisiete esclavos huidos que allí se resguardaban, construir una iglesia al nuevo santo San Basilio, obedecer a las nuevas autoridades civiles (párroco, alguacil y alcalde), y en caso de guerra, a alistarse en la defensa de Cartagena (Cimarrones 113). De modo que la firma del documento que históricamente testifica la condición de Palenque como "pueblo libre" y da origen a la mitificación de Palenque como "El primer pueblo libre de América”, simultáneamente marca la cancelación de la libertá cimarrona con la incorporación jurídica del palenque en el orden socio-racial del imperio español.

A pesar de que la mayoría de los especialistas contemporáneos coinciden en considerar la historia de Biojó como un elemento exógeno, el actual Palenque de San Basilio se identifica simultáneamente con el legendario Palenque de Benkos Biojó fundado en 1603 y con el palenque de San Miguel reconocido con la Entente Cordiale en 1713. ${ }^{6}$ A fin de cristalizarse como un relato coherente, el mito de la libertad palenquera necesariamente implanta una serie de operaciones retóricas -elipsis, digresiones, inserciones- en la historia escrita sobre el movimiento cimarrón, lo que deriva en una reducción representativa, un esfuerzo público por mediatizar el Palenque como "El primer pueblo libre de América". Así las cosas, la historia de San Basilio de Palenque evoluciona hacia la reformulación de la inicial experiencia cimarrona de la libertá en la posterior noción criolla de "independencia", a partir de la mitificación de una operación jurídica excepcional: la inclusión del palenque de San Miguel en la extensión soberana

6 A pesar de esta tendencia general, algunos palenqueros ya están incorporando los aportes de Navarrete. Tal es el caso del artículo escrito por el palenquero Alfonso Cassiani Herrera, "300 años ... (Cocina palenquera 108-12), reporta la gesta de Benkos en La Matuna entre 1599 y 1621, la destrucción del palenque de San Miguel en 1694 en los montes de María y su refundación por el capitán Nicolás de la Rosa, el verdadero fundador de San Basilio en 1713.

$111 \frac{\text { Revista Iberoamericana, Vol. LXXXII, Núms. 255-256, Abril-Septiembre 2016, 597-618 }}{\text { ISSN 2154-4794 (Electrónico) }}$ 
de la gobernación de la Corona Española. ${ }^{7}$ El mito libertario lleva a cabo una sustitución sintáctica temporal, insertando la heroica resistencia del capitán cimarrón como causa directa de la firma de la Entente Cordiale ciento diez años después.

El mito libertario del capitán Biojó ha sido rescatado por el programa "La ruta del esclavo" de la UNESCO y materializado en el monumento a Benkos Biojó instalado en el pueblo en 1995. El reconocimiento a Palenque como "Obra Maestra del Patrimonio Inmaterial de la Humanidad" por la UNESCO en el 2005 impulsa la pervivencia del mito libertario de los palenqueros. A partir de este momento, Palenque recibe atención sin precedentes por parte de los medios de comunicación, de instancias gubernamentales y organismos internacionales de cooperación. De esta manera y en pocos años, Palenque pasa de ser un poblado "perdido" de los Montes de María y un interés científico particular, a ser el emblemático "primer pueblo libre" asimilado a una renovada identidad nacional que reconoce sus orígenes con la celebración del Bicentenario de su independencia. Este, en su inherente fantasmagoría, inscribe en el retorno de lo histórico la repetición diferenciada de una tropología nacional, evidente tanto en la recuperación de términos como 'libertad', 'independencia', 'memoria revelada', como en el uso de prefijos de repetición (renovación, reconocimiento) y duplicidad (bicentenario). ${ }^{8}$

\section{LA LLEGADA DE LA HISTORIA Y LA CONSIGNACIÓN DE SU ARCHIVO}

La existencia del palenque de San Basilio fue prácticamente desconocida hasta la construcción del primer camino que comunicaba el pueblo con las ciudades aledañas de Malagana y Cartagena en 1954. En este mismo año, el etnólogo Aquiles Escalante llega a San Basilio a investigar la lengua y cultura de los palenqueros y los resultados de esta primera investigación son consignados en su estudio "Notas sobre el palenque de San Basilio, una comunidad negra en Colombia". Sin embargo, no fue hasta los años setenta y ochenta, cuando un número importante de académicos (Bickerton, De Granda, de Friedemann, Patiño Roselli, Schwegler, Moñino y Morton) retoman la pista dejada por Escalante y establecen una práctica investigativa in situ, que inicia un proceso de reconocimiento del Palenque por las esferas académicas, institucionales y

\footnotetext{
7 Opera aquí un deslice moderno de las palabras 'libertad' y 'libre'. En tiempos coloniales, la 'libertad' era parte integrante del sistema esclavista: a un buen esclavo obediente y conforme se le otorgaba la 'libertad', se volvía un hombre 'libre'-que a su vez podía tener esclavos (por ejemplo en un censo hecho en 1772, cuarenta años después de la firma de la Entente Cordiale San Basilio contaba con 359 'libres’ y 90 esclavos)-. Es en este sentido que Palenque es el primer pueblo 'libre' de América y no en el sentido dado por la recuperación estatal y sus connotaciones de la 'libertad-igualdad-fraternidad' que informa la oficialidad de los estados modernos.

8 Por ejemplo, como parte de la conmemoración del bicentenario de la independencia, el canal nacional Señal Colombia financió un corto animado sobre Benkos para la serie Bicentenario: memoria revelada. El video está disponible en $<$ www.youtube.com/watch? $\mathrm{v}=\mathrm{S} 6 \mathrm{~s} 0 \mathrm{BR} k \mathrm{GGSc}>$.
}

$111 \frac{\text { Revista Iberoamericana, Vol. LXXXII, Núms. 255-256, Abril-Septiembre 2016, 597-618 }}{\text { ISSN 2154-4794 (Electrónico) }}$ 
estatales. Por una parte, el resultado de las investigaciones científicas ha devenido en la identificación y estudio de la singularidad cultural y lingüística de Palenque, la cual ha motivado el reconocimiento de Palenque por la UNESCO como "Obra Maestra del Patrimonio Inmaterial de la Humanidad" en el 2005. Por otra parte, las sucesivas interacciones entre los palenqueros y los académicos han generado la integración del debate histórico sobre los “orígenes míticos" del palenque en la discursividad identitaria de los palenqueros. Para Schwegler, este proceso de "reinvensión etnohistórica" se inicia con los viajes de campo de investigadores en la década de 1970 en los cuales se instalaron las primeras identificaciones de los palenqueros como bantúes y cimarrones:

Cuando se le preguntó a los palenqueros de qué parte de África venían sus antepasados, no respondieron, o explícitamente aceptaron no saberlo. Sin embargo, algunos palenqueros exclamaron con orgullo:¡somos bantú!”. Entre ellos Raúl Salas Hernández, un hablante competente y orgulloso de la lengua [...] el término "bantú" se originó en Europa en el siglo XIX, y fue introducido al Palenque por pioneros de la investigación como Nina de Friedemann, Richard Cross and Carlos Patiño Rosselli, quienes se hospedaron en casa de Raul Salas durante el trabajo de campo. ("Sobre el origen" 115)

Por una parte, la "revelación" de los orígenes africanos de los palenqueros por la investigación académica instala un dialogismo fundacional en la discursividad identitaria palenquera como reiteración de la huella letrada de su historia. Con lo cual, las "huellas de africanía" enunciadas por la antropóloga Nina de Friedemann no sólo identifican sino que prescriben una impronta interpretativa que luego es integrada a la configuración ideológica de los mecanismos de reconocimiento estatal e internacional del Palenque como "África en América".9 Con lo cual, la observación de Schwegler permite ver cómo la producción del relato histórico de Palenque está marcada por el signo de la llegada, por la incursión foránea que devela la "verdad" ignorada por los mismos cimarrones: las huellas africanas que preceden sus pasos como primer pueblo libre de América.

Es a partir de 1954 con la llegada de Aquiles Escalante al pueblo que el relato histórico de Palenque se inscribe como un proceso secuencial -descubrimiento, excepcionalidad y reconocimiento- detonado exclusivamente por la llegada del

\footnotetext{
9 Según de Friedemann, los palenqueros contemporáneos actúan siguiendo una codificación cultural interna heredada de forma inconsciente de sus antepasados africanos, "bagaje cultural sumergido en el subconsciente de los africanos esclavizados, [que] se hace perceptible en la organización social, en la música, en la religión o en el teatro de carnaval de sus descendientes" ("Vida y Muerte" 84). De esta manera, son las instancias liminales de conciencia como es el caso de los funerales, umbral entre la vida y la muerte, las que privilegian la manifestación de la huella: "Cuando el muerto ha pertenecido al Lumbalú, el tambor retumba las nueve noches del velorio y en los cánticos reaparecen los vocablos kikongo [...] con el aura africana de creencias religiosas saturadas de espíritus" ("El santo" Ma Ngombe).
}

$111 \frac{\text { Revista Iberoamericana, Vol. LXXXII, Núms. 255-256, Abril-Septiembre 2016, 597-618 }}{\text { ISSN 0034-9631 (Impreso) }}$ 
agente externo al enclave cimarrón, y del advenimiento de la escritura de la historia que con él acaece. Nuevamente es Schwegler quien nos da acceso a este proceso de producción letrada:

My multiple extended stays in Palenque (1985 to 1996, and 2008) confirmed that, prior to the first arrival of scholars in the community in the $1950 \mathrm{~s}$ and then again in the 1970s and 1980s, the Palenqueros had no collective memory of the slave trade in general, nor of any other historical events that predated the 1900. ("Palenque(ro): The Search for its African Substrate" 12) ${ }^{10}$

La llegada de la historia es presentada por Schwegler como aquello que suple una doble falta fundamental: la ausencia de conocimiento y de memoria colectiva de la historia de su explotación como descendientes de africanos esclavizados por el régimen colonial español, y el lugar que la historia cimarrona de los palenqueros tiene en la historia de la humanidad y de la nación. En este sentido, la llegada del investigador completa el vacío histórico producto del aislamiento de la comunidad palenquera, a la vez que revela el pasado histórico que otorga sentido al presente palenquero. Como afirmación, la explicación de Schwegler invita a la interrogación de sus propios límites. Dado que los palenqueros han efectivamente experimentado la violencia de los remanentes contemporáneos de una historia de la esclavitud -en las diferentes instancias y mecanismos de exclusión legal y socioeconómica de las comunidades afrocolombianas ${ }^{11}$ ¿a qué refiere esta carencia, esta "doble falta fundamental" que señala Schwegler?

$\mathrm{Al}$ respecto, la lectura derridiana del concepto hegeliano de la historia en la cuarta sesión del curso Heidegger: La question de l'Être et l'Histoire (11 de enero 1965) nos otorga herramientas de interrogación crítica. Tomando como punto de partida la contemporaneidad y co-substancialidad de la efectividad histórica (Geschichte) con su relato, vemos que esta percepción de la conciencia histórica palenquera, o mejor, de la ausencia de ella, recuerda a la noción hegeliana de Mnemosyne, la capacidad -o incapacidad- de una comunidad de re-citarse a sí misma a lo largo del tiempo. Para Hegel la narración y la experiencia histórica son inseparables: la conciencia de la historia

${ }^{10}$ Esta afirmación es desambiguada en la traducción del ensayo en 2012: "Mis múltiples visitas a Palenque (1985-1996 y 2008) confirman que, antes de la llegada de los primeros investigadores en las décadas de los cincuenta, setenta y ochenta, los palenqueros no contaban con una memoria colectiva sobre la trata de esclavos ni sobre datos históricos anteriores al siglo XX" (Sobre el origen 115) (La cursiva es mía). El problema de la memoria histórica no es tema cerrado en Palenque. Moñino ha recogido relatos de eventos históricos en Palenque que aunque posteriores a la esclavitud se remontan hasta 1812. También ha recopilado usos despectivos de la palabra "esclavo" por los palenqueros (C.P. Moñino).

${ }^{11}$ La Constitución Política de 1991 reforma la Constitución de Rafael Núñez vigente desde 1886. Bajo la nueva Constitución, Colombia se define como un país plurilingüe y multicultural. Sin embargo, no es hasta 1993 que las comunidades afrocolombianas son legalmente incluidas en la Constitución.

$111 \frac{\text { Revista Iberoamericana, Vol. LXXXII, Núms. 255-256, Abril-Septiembre 2016, 597-618 }}{\text { ISSN 2154-4794 (Electrónico) }}$ 
de un pueblo es histórica (Geschichtlich) a partir del momento en que este es capaz de producir sus propios signos para narrar su experiencia (Derrida, Heidegger 158-59). Para Hegel vivir históricamente solo es posible si se tiene el lenguaje y la conciencia, además de la experiencia: "In our language the term History unites the objective with the subjective side, and denotes quite as much the historia rerum gestarum, as the res gestae themselves; on the other hand, it comprehends not less what has happened, than the narration of what happened" (Hegel 60), dando a entender al mismo tiempo que no hay historia estrictamente individual, sino del pueblo o del Estado. Recordemos que para Hegel el proceso de narración histórica no es ni personal, ni testimonial: es un procedimiento ligado a la constitución del Estado y por lo tanto, no existe la historia individual desligada del Estado:

Family memorials, patriarchal traditions, have an interest confined to the family and the clan. The uniform course of remembrance which such a condition implies, is no subject of serious remembrance [...] But it is the State which first presents subject matter that is not only adapted to the prose of History, but involves the production of such history in the very progress of its own being. (60-61)

Por lo tanto, en la reflexión hegeliana, la relación entre Estado e historia es recíproca: el Estado es el origen de la historia y a su vez no puede prescindir de ella: no hay historia sin Estado y el Estado sin historia está incompleto. Por esta razón para Hegel, un pueblo que no se constituye en un Estado guardián de sus instituciones y de su patrimonio histórico, es un pueblo que no tiene historia (Geschichtlich) (Derrida, Heidegger 158). Derrida lee esta presentación de subject matter precisamente como la proporción y medida de una forma universal e histórica: "Cela signifie que l'État fournit une matière déjà universelle et objective dans sa signification et dans cette mesure déjà apte à nourrir la forme universelle du récit et de la science historique" (Heidegger 159). Derrida explica cómo el Estado no solamente es capaz de recoger y reunir (recueillir) la materialidad co-substancial en instituciones de consignación como los monumentos, las bibliotecas, los museos - es decir, el Estado no solo organiza racionalmente los signos y las obras históricas en el espacio- sino que los produce: “[...] il produit ces signes et des signes aptes à circuler de façon rationelle, transparente et universelle et univoque (volonté générale)" (Heidegger 159).

Por lo tanto, la pregunta ya no remite a la supuesta ignorancia de los palenqueros con respecto a su memoria colectiva de la historia de la esclavitud, sino a la producción de la substancialidad histórica del récit palenquero por la materialidad objetiva y la forma universal del relato histórico producida "en con-signación" en el archivo histórico del Estado. En el caso de Palenque, la producción de la materialidad del relato histórico y su consignación en la historia nacional de Colombia, implica también un proceso en el que los signos se con-signan -se depositan y entregan- como los signos de la

$111 \frac{\text { Revista Iberoamericana, Vol. LXXXII, Núms. 255-256, Abril-Septiembre 2016, 597-618 }}{\text { ISSN 0034-9631 (Impreso) }}$ 
historia y el archivo universal de la humanidad -y del Estado-. Tanto en la medida en que la estructura técnica del archivo determina la estructura del contenido archivable, como su relación con el futuro: "the technical structure of the archiving archive also determines the structure of the archivable content even in its coming to existence and in its relationship to the future. The archivization produces as much as it records the event" (Archival 17).

De esta manera la declaración de Schwegler nos da pie para interrogar la ficción de compleción y develación histórica, no únicamente como la revelación de hechos históricos ignorados por la comunidad, sino como el diagnóstico que precede y permite la implementación de un lenguaje y una episteme histórico-científica (historein). La llegada de la historia a hombros de los primeros investigadores, identificada en esta frase de Schwegler, marca un momento y un movimiento claves en la conformación discursiva, en la progresiva consignación archivólica de Palenque en la historia de la nación. Identificado por Derrida en su texto Mal de Archivo, el principio arcóntico del archivo convoca tanto el poder de consignación, la reunión, apropiación de los signos; como la toponomología, la domiciliación de la ley del archivo -y del archivo como garante de la ley-. En la formación del archivo opera una voluntad patriárquica de marcar residencia y ley (nomos) que es también una voluntad de "unificación, identificación, clasificación" coordinada por el poder de consignación, el poder de reunir los signos en un solo corpus: "en un sistema o en una sincronía en la que todos los elementos articulan la unidad de una configuración ideal" (Mal 11). Esta voluntad que aspira a una configuración sin disociaciones, ni silencios, ni heterogeneidades disonantes, está sin embargo, amenazada por el a priori destructivo del archivo: "It destroys in advance its own archive, as if that were in truth the very motivation of its most proper movement. It works to destroy the archive" (Archive 9). Por lo tanto, la narración reflexiva de la llegada de la esfera letrada al palenque, es un síntoma de la progresiva incorporación del palenque, hasta ese momento por fuera de la historia, como patrimonio, archivo y monumento.

A la luz de la función arcóntica desplegada por la fuerza consignataria del Estado, podemos entender el paso de la esfera letrada dentro del palenque como el paso que irremediablemente precede el reconocimiento de la UNESCO como patrimonio de la humanidad: un paso que anuncia la reinscripción y consignación del relato palenquero en la narración y el archivo históricos del Estado colombiano -y que por tanto, demanda en quien escribe una responsabilidad crítica con respecto al relato oficial-. En este aspecto, es en la escritura crítica, aquella que desmitifica y perturba la homogeneidad del relato histórico oficial, que podemos leer las huellas del trabajo de la des-monumentalización.

Dentro del marco hegeliano y bajo la figura legal del reconocimiento, el Estado colombiano reterritorializa la fuga y lucha palenquera como herencia histórica de la nación, efectuando la subsunción de la libertá cimarrona en el marco republicano 
de la independencia nacional. A esta conformación le precede la pérdida que se inaugura con la llegada de los académicos, un cierto cubrimiento que se despliega con el descubrimiento científico: la revelación del relato histórico oficial y del relato científico implican simultáneamente el hecho de velar la substancialidad del relato palenquero en la experiencia del tiempo. En este sentido, asumir que la conciencia histórica de su libertad originaria es despertada en el palenquero por el investigador, es limitar la conciencia de dicha libertad a su registro histórico. Es decir, en primera instancia, limitarla a los parámetros legales que codifican la propiedad de la tierra y los derechos civiles estipulados por el discurso jurídico de la Corona y, en segunda instancia, a la recuperación de la libertad por el aparato cultural estatal. Con lo cual, la monumentalidad oficial del primer pueblo libre de América queda organizada alrededor de un vacío fundamental: el relato (récit) cimarrón de la libertad.

Es así como la pregunta por la historia de Palenque es también la pregunta por su relación con el archivo, sus aparatos de consignación y fundación, y, con aquello con que se abre en la lectura derridiana: el a priori destructivo de toda consignación. En aquello mismo que permite y condiciona el archivo, la exterioridad que asegura la repetición y la memoria, encontramos el olvido, la amenaza de su destrucción. No hay deseo de archivo sin pulsión de muerte, sin la intimidante posiblidad de olvido. Esta pulsión de muerte, contraria a la producción de signos o a su re-citación, expropia silenciosamente, es una pulsión muda (stumm) que nunca deja que un archivo le sea propio: "destruye su propio archivo por adelantado ... Trabaja para destruir el archivo: con la condición de borrar, mas también con el fin de borrar sus "propias" huellas ... Devora su archivo, antes incluso de haberlo producido, mostrado al exterior" (Derrida, Mal 18). Esta pulsión de muerte definida por Derrida como anarchivística, archivolítica, es la pulsión muda e (in)operante que trabaja en contra del monumento a Benkos Biojó.

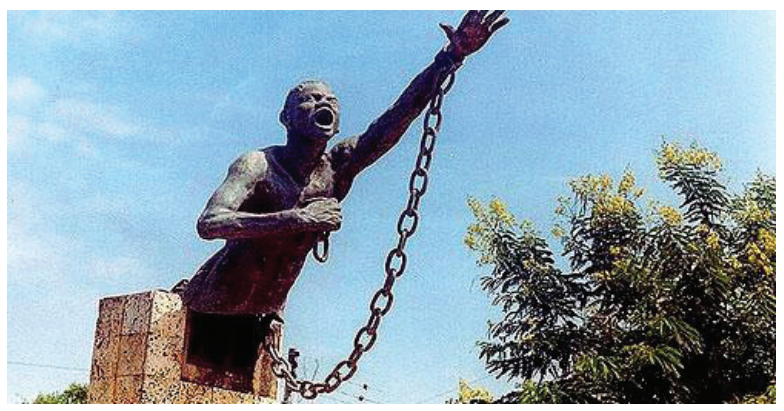

Figura 1. Monumento a Benkos Biojó. San Basilio de Palenque. Foto. Ludmila Ferrari, 2010.

$111 \frac{\text { Revista Iberoamericana, Vol. LXXXII, Núms. 255-256, Abril-Septiembre 2016, 597-618 }}{\text { ISSN 0034-9631 (Impreso) }}$ 
En 1995 el proyecto científico institucional Expedición Humana, dirigido por la Pontificia Universidad Javeriana, comisionó en colaboración con el programa La ruta del esclavo (UNESCO) la construcción del "Monumento a la libertad" al pintor y escultor colombiano Luis Guillermo Vallejo Vargas. ${ }^{12}$ El monumento resultante consiste en un busto de bronce que retrata a Benkos Biojó, líder de la resistencia palenquera y supuesto fundador de San Basilio de Palenque, en el instante mismo de su liberación: rompiendo con un grito las cadenas de la esclavitud y extendiéndose hacia el cielo en una alegórica diagonal libertaria (Figura 1).

$\mathrm{Al}$ igual que otras de las esculturas conmemorativas instaladas por el programa La ruta del esclavo -como es el caso del monumento a "Yanga" en Veracruz, México y el "Monumento al Cimarrón" en Santiago de Cuba- el monumento a Biojó representa y conmemora la libertad negra utilizando los elementos formales del canon monumental occidental: concentricidad ortogonal, elevación e interpelación de la mirada del espectador, y expresividad de un geist heroico. ${ }^{13}$ Los tres casos también coinciden en la elección de una figura masculina que se erige solitaria por encima de la línea de horizonte. Ya sea con la ayuda de pedestales o por determinates paisajísticos, como el relieve montañoso de Santiago de Cuba, los monumentos de cimarrones de la UNESCO se encuentran siempre elevados en soledad hacia una dimensión superior. Ubicados en las áreas ocupadas por antiguos palenques, los monumentos de La ruta del esclavo fueron concebidos como dispositivos visuales de reconocimiento oficial de la presencia cimarrona en América Latina. ${ }^{14}$ Financiados por la lógica del reconocimiento de la UNESCO estos monumentos necesitan ser interrogados en su conceptualización e imposición alegórica de la experiencia de lucha de comunidades afrolatinoamericanas como la de San Basilio de Palenque. Estas piezas constituyen una representación institucionalizada de la resistencia armada de los cimarrones, quienes precisamente, al "romper con las cadenas" del régimen esclavista se liberaron de la institucionalidad colonial que legitimaba la pervivencia generacional de su inhumana subyugación. La serie de elecciones plásticas propias de una conceptualización del monumento como unidad fálica de sentido - es decir, como individualidad erecta, impenetrable y metálica- no solo ignora el carácter colectivo y

12 Vallejo Vargas es autor de dos de los monumentos históricos más reconocidos del país: el "Monumento a los colonizadores" en el cual evoca la colonización antioqueña en el Viejo Caldas y el "Monumento a los Comuneros" en Santander en donde Vallejo conmemora la Revolución de los Comuneros y su líder José Antonio Galán ("Teatro Azul, Almas Unidas en Magia de Colores").

${ }_{13}$ Para una descripción más detallada de estos elementos consultar "Palenque un performance de la libertad" Ferrari, 2012.

${ }^{14}$ Consultar: "La ruta del esclavo". <http://www.unesco.org/new/es/social-and-human-sciences/themes/ slave-route/>. 
heterogéneo de la resistencia cimarrona, sino que instala una representación-esencialista de su lucha por la libertad.

A diferencia de otros monumentos de la Ruta del Esclavo, el monumento de Benkos Biojó tiene una función fundadora además de conmemorativa-representativa; lo cual permite trazar una interrogación no ya desde una perspectiva identitaria y representacional de la voluntad de simbolización aquí concentrada, sino desde la reiteración del gesto originario, fundacional, que se recoge (recueille) materialmente en la escultura. Por tanto, podemos leer el monumento como huella de la consignación de la substancialidad histórica del récit palenquero así como del "mal" que amenaza el archivo con la posibilidad de su destrucción. En este sentido, la escultura de Benkos Biojó está primariamente conectada con la misión conmemorativa/fundadora desplegada por la UNESCO y su programa La ruta del esclavo; con lo cual el monumento hace efectiva a través de la conmemoración del poder originario y arcaico (arkhē) de la fundación mítica de Palenque por Biojó, la instalación y consignación del poder arcóntico de la UNESCO. De esta forma, no solo se podría decir que el monumento a Benkos Biojó precede y produce la constitución de Palenque como monumento de la nación, sino que paradójicamente es a través de una ideologización republicana de la libertad como componente identitario y originario de los palenqueros que se hace efectivo el archivo y patrimonialización de Palenque en el territorio simbólico de la nación.

Esta lectura parte de la sospecha de la aceptación del monumento como una obra terminada y perteneciente al palenque, así como de su constante asociación con el título de Palenque como Obra Maestra del Patrimonio Intangible de la Humanidad. Esta noción de "obra completa" es la que vemos reaparecer en la exposición "Del monumento al pensamiento": una clara afirmación de que el monumento ya está y ahora hay que pensarlo, admirarlo, como una "obra maestra" más incorporada al archivo de la UNESCO y a su programa de intangible heritage. ${ }^{15}$ Por el contrario, lo que la presente lectura busca mostrar es el proceso inacabado de constitución del monumento, desde su entrega a la comunidad en 1995 hasta la renovación del área circundante en el 2014. Un proceso marcado por diferentes instancias anti-monumentales de desplazamiento y borradura.

La epopeya de este Benkos escultórico se inaugura cuando llega al Palenque en manos de Nina de Friedemann y Guillermo Vallejo en 1995 ("Benkos" 215). La llegada de la

\footnotetext{
${ }^{15}$ No hay espacio aquí para presentar las críticas que Smith and Akagawa, Intangible Heritage (Key Issues in Cultural Heritage) y Barbara Kirshenblatt-Gimblett, "Heritage as Metacultural Production" hacen a la noción de la UNESCO de Intangible Heritage como componente esencial del "Authorized Heritage Discourse" (AHD). Este discurso dicta los criterios de aprobación y regula el valor del patrimonio -su valor de preservación-, a la vez que liga una política estatal a la industria cultural del capitalismo globalizado. Varios de los elementos de esta crítica son elaborados en el texto de Kirshenblatt-Gimblett, "Theorizing Heritage".
}

$111 \frac{\text { Revista Iberoamericana, Vol. LXXXII, Núms. 255-256, Abril-Septiembre 2016, 597-618 }}{\text { ISSN 0034-9631 (Impreso) }}$ 
escultura tuvo un carácter congregacional, ya que convocó a la comunidad palenquera tanto en términos representativos (el pueblo de Palenque como los descendientes de Benkos Biojó) como religiosos (es la congregación de la iglesia la que sitúa en simbólica vecindad, la figura de Benkos y la figura de San Basilio en el altar de la iglesia del pueblo). ${ }^{16}$ De este modo convivieron en el espacio y la causalidad histórica, los dos agentes pacificadores San Basilio - pacificador civilizador que reinscribe al palenque cimarrón dentro de los límites de la ley de la Corona-y Benkos, figuración contemporánea del mito libertario que inscribe a palenque en un régimen globalizado de lo local-nacional.

¿Cómo leer las diversas relaciones que se generan entre estas dos esculturas? Sin duda encontramos aquí la reiteración y reactualización del pacto de incorporación del Palenque en los dominios soberanos. Con una diferencia éstos ya no son los dominios territoriales del poder colonial de Cartagena, sino la geopolítica cultural de la UNESCO articulada con la política cultural del Estado colombiano; y la escultura no es la de un santo español (San Basilio), sino la figuración de Benkos Biojó, la interpretación de la libertad cimarrona por parte de una retórica visual occidental. ${ }^{17}$ Si la escultura de San Basilio muestra a los palenqueros aquello que no son, la escultura de Benkos monumentaliza una versión de lo que son y de lo que deben ser. Recordemos que el monumento como archivo ejerce un poder unificador e identitario (consignación) que es también un mandato de ley (nomos) que organiza la previsión de un porvenir. Y es también en este sentido que se reitera el pacto de pacificación de los cimarrones, pero no ya como un pacto de no-intervención, sino como todo lo contrario; en esta reiteración consignataria, el Estado celebra, visibiliza y hace monumental al Palenque. La visibilización mediática e institucional de este "pedazo de África en América" completa un paisaje político de Colombia como un país pluriétnico, a la vez que renueva la sumisión y traspaso del poder representativo de los cimarrones al Estado.

La escultura de Benkos no duró mucho tiempo dentro de la iglesia, ya para 1997 había sido instalada sobre un pedestal en el terreno frente a la iglesia. Esta primera instalación de la escultura, su constitución como monumento, presentaba una importante desproporción entre el pedestal de cuatro metros de altura y el busto de bronce tres veces más pequeño. Una mirada más cercana permitía reparar en las diferencias materiales y técnicas entre la figura correctamente modelada y vaciada en bronce, y el pedestal de factura rudimentaria hecho de cemento y baldosas de granito. Este primer

16 La escultura de Benkos fue guardada en la iglesia mientras se construía el pedestal. Durante este periodo previo a la monumentalización, el busto de Benkos era visitado y tratado por los/as palenqueros/as como una figura oferente (Yves Moñino, c/p enero 2015).

17 Existe otro busto de Benkos en Cartagena ubicado en el monumento a la Constitución de 1886 adyacente a la casa-museo del ex-presidente Rafael Nuñez (quien redactó dicha carta constitucional). El monumento ubica a Benkos junto con bustos de dirigentes criollos del XIX y a Cárex un indígena que enfrentó a los españoles en los principios de la conquista. Para un análisis de las políticas étnicas de este monumento consultar el texto de Elizabeth Cunin, A flor de piel. 
pedestal fue construido por los habitantes del pueblo con los materiales disponibles y no con aquellos destinados para la terminación del monumento. Por esta razón, y pesar de ser un monumento oficialmente financiado por la UNESCO, la escultura de Palenque carecía de una placa conmemorativa oficial. La ausencia del rótulo dejaba al descubierto una sección del zócalo blanco sobre la cual se escribió el primer epígrafe del monumento: "Palenke Fundado por BENKOS BIOHO en 1603". Vemos en esta primera denominación escrita la marca de un reclamo fundacional por los palenqueros contemporáneos (aquí Palenke) designado con la fecha del mítico palenque fundado por Biojó. Este primer epígrafe, incorrecto, apela al palenque originario, inasible y siempre diferido. La escultura de Vallejo otorga una substitución figurativa, una forma con clara voluntad originaria y teleológica: no es Palenke sino Benkos Biojó. Sin embargo, esta voluntad identitaria es desestabilizada por el epígrafe en que el nombre del pueblo escrito en lengua palenquera antecede al nombre del héroe. Este epígrafe, cimarrón con respecto a su propio monumento, efectúa una fundación retrospectiva de Palenke por los palenqueros contemporáneos, una fundación anterior a la pacificación de 1713 que toma posesión frente a la iglesia de San Basilio.

Inevitablemente, un par de años después, el nombre del pueblo y la nominación conmemorativa del epígrafe fueron corregidas, la nueva dedicatoria leía: "BENKOS BIOHO fundador de Palenque. 1603”. La reorganización sintáctica del nuevo epígrafe buscaba estabilizar el desplazamiento fundacional generado por la firma no-autorizada del monumento como "Palenke", y reinscribir el monolito en la forma universal de la conmemoración histórica del héroe. Este nuevo epígrafe mantenía la fecha de la fundación mítica (1603), celebrando la ficción de una fundación histórica, bajo un símbolo correcto de libertad (Figuras 2 y 3). Sin embargo, es en este momento que el monumento revela plenamente su contradicción: la libertad cimarrona atada al pedestal de cemento por cadenas de la esclavitud. Y es al poco tiempo que los palenqueros arrancan las cadenas de los brazos de la figura, despojando a la escultura de su alegoría, descompletando la sintaxis mitológica del monumento y desnudando un grito libertario enmudecido.

Esta enmienda de la norma léxica-monumental: el reemplazo de la [ $\mathrm{ka}$ ] Kikonga de "Palenke", de Benkos, por la [que] del "Palenque" hispanizado, torna incorrecto el nombre y nombramiento palenquero en favor de la elevación "correcta" del monumento. Este acto de reescritura es también el silenciamiento y el entierro del nombre propio que precede a la elevación del monolito. Así, el monumento emerge con la tumba del nombre y por tanto, con el nombre como tumba. "Palenque" se erige con/sobre esta letra enterrada, la [k]silenciada, fantasmática. En este sentido, el monumento ("the tomb of the proper name") es el sitio en donde cae [tombe] y se difiere esta diferencia inaudible [ke/que] que desautoriza la escritura fonética y activa el juego silencioso de la différance en el corazón del epígrafe. La différance, "not a word and not a concept", se opone a la secundariedad provisional originaria y teleológica del signo saussureano

$111 \frac{\text { Revista Iberoamericana, Vol. LXXXII, Núms. 255-256, Abril-Septiembre 2016, 597-618 }}{\text { ISSN 2154-4794 (Electrónico) }}$ 

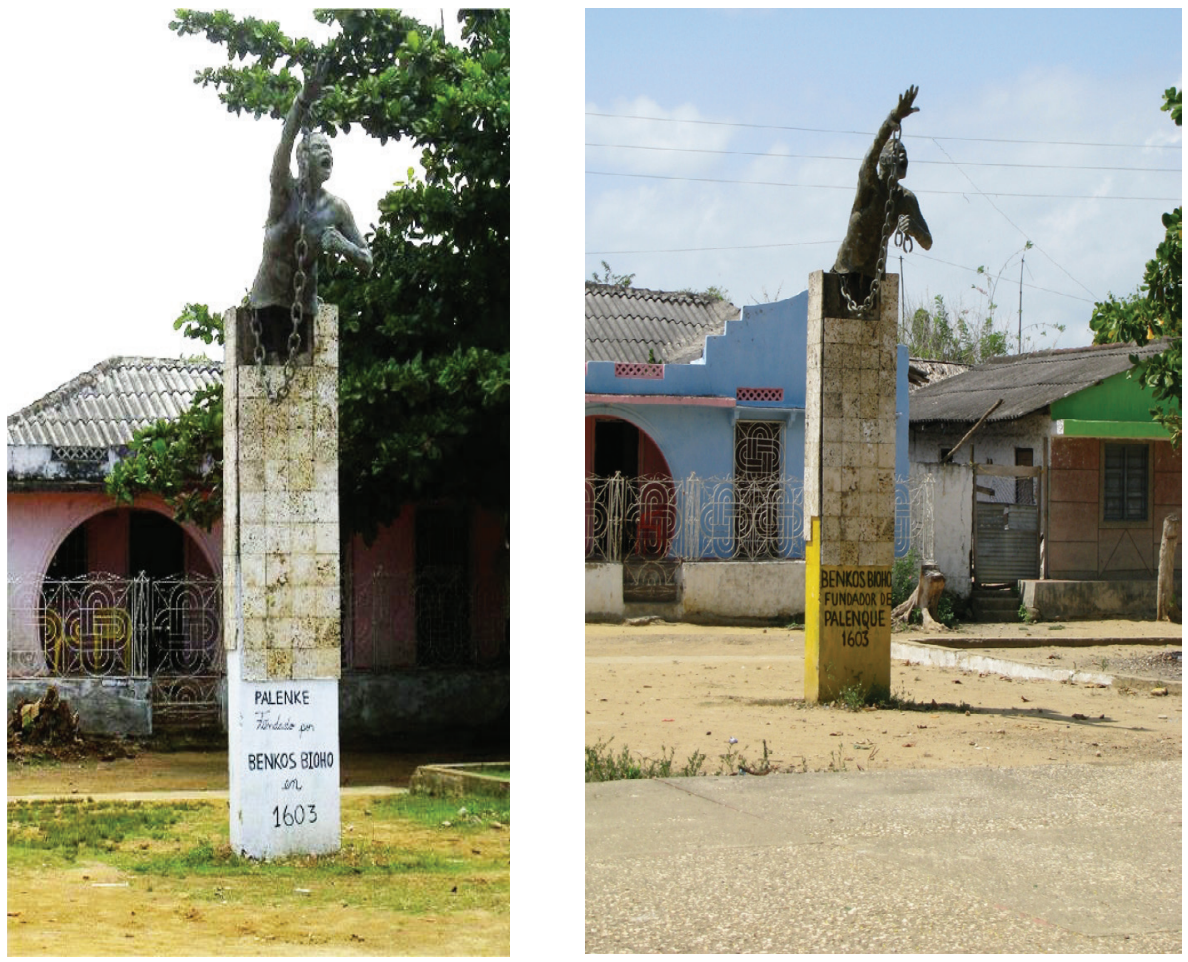

Figuras 2 y 3. Aquí se pueden ver los dos epígrafes. Foto. Yves Moñino, 2009.

-el signo como un efecto producido por una causa (sujeto o sustancia) primaria y final- cuestionando la autoridad de la presencia y su opuesto simétrico, la ausencia:

This graphic difference (a instead of e), this marked difference between two apparently vocal notations, between two vowels, remains purely graphic: it is read, or it is written, but it cannot be heard [...] It is offered by a mute mark, by a tacit monument $[\ldots]$ The a of différance, thus, is not heard; it remains silent, secret and discreet as a tomb: oikēsis. (Derrida, "Différance" 4)

El juego silencioso de la différance, su inaudible diferencia resiste la oposición entre lo sensible y lo inteligible al ubicar su "middle voice" entre la escritura y el habla. La escultura como signo y no como la cosa, es en la mirada semiológica, secundaria a una presencia originaria y perdida, y provisional al arribo (siempre diferido) del significado completo (Derrida, "Différance" 9). En este sentido, la différance resiste su presentación: "being-present in its truth, in the truth of a present or the presence 
of the present" (5). Como "estrategia sin finalidad" el trabajo de la différance no está orientado hacia una trascendencia del significado, ni hacia su presentación completa, sino al desplazamiento de lo ontoteológico.

El silencio enterrado en el nombre-monumento de Palenque revela en la escultura el movimiento archi-escritural y sin origen de la différance. La [k] silenciada, marca el intervalo (spacing) que por una parte difiere la promesa de presentación del nombremonumento y por otra desplaza el mandato del monumento sobre el porvenir. Así la [k] borrada marca el intervalo que separa el presente de aquello que no es, instalando en la inscripción misma del nombre del pueblo el trazo de su diferencia, traicionando el mandato y la ansiedad de fijación identitaria del monumento. Esta borradura no consigue "eliminar" sino que por el contrario, contribuye a marcar el constante movimiento de no-presentación del trazo: "The trace (of that) which can never be presented, the trace which itself can never be presented. The trace is never as it is in the presentation of itself. It erases itself in presenting itself” (23). Esta dinámica del trazo y la borradura que desestabiliza la voluntad esencialista del monumento es luego cancelada por una voluntad represora del juego del significado y de su apertura al porvenir; una voluntad de concreto que responde al movimiento subversivo de la escritura (écriture) con el encierro definitivo del epígrafe dentro de un pedestal escalonado construido en el 2010 (Figura 4).

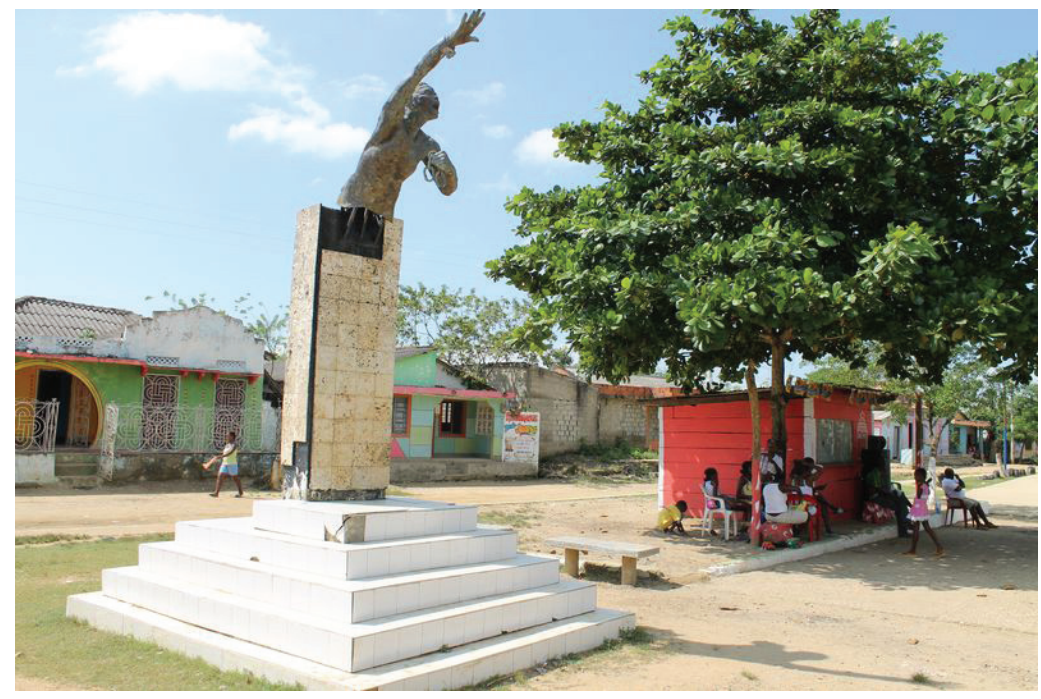

Figura 4. Pedestal escalonado cubriendo la porción del pedestal destinada al epígrafe. 2010 
Es así como en pocos años y de manera esporádica se suceden importantes modificaciones al monumento. En estas vemos cómo el despliegue de una economía compensatoria, substanciada en adiciones de cemento y mosaico, elimina la posibilidad de (re)escritura del monumento, expandiendo la gramática material y organizacional del Estado dentro del palenque. La modificación del 2010 sólo anunciaba la futura urbanización del área circundante al monumento y la instalación de una placa oficial por el gobierno dos años más tarde. Actualmente, el piso que rodea al monumento, epicentro de la "renovación" del pueblo, ha sido marcado por una serie de líneas de proyección
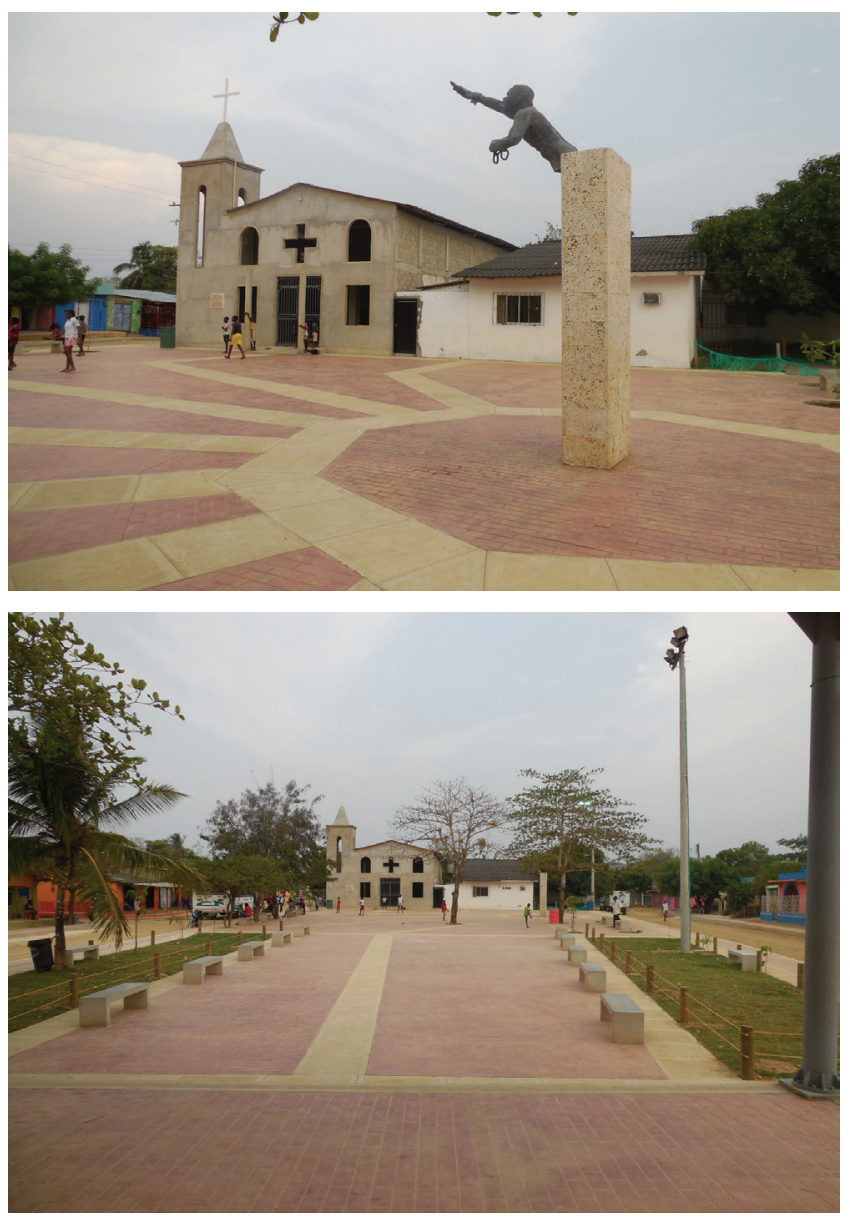

Figuras 4,5,6. Muestran la progresiva urbanización de el área de la plaza en San Basilio de Palenque. Foto. Yves Moñino, 2012 y 2014. 
que otorgan gráficamente un carácter heliocéntrico al monumento. De esta manera, el monumento funda un nuevo régimen espacial, un nuevo centro en el palenque y articula una unidad infraestructural plaza-escultura-iglesia con la calle principal y la entrada al pueblo (Figuras 5 y 6). Si bien esta reconstrucción no repite el esquema de damero propio de la colonización hispánica, sí instala un régimen espacial ortogonal diferente del modelo espacial del kuagro palenquero organizado en rectángulos concéntricos. De esta manera, la discordancia entre la escultura y el pueblo, evidente en los primeros años de su instalación, ha sido superada por la adaptación infraestructural del palenque al monumento. Es así como el monumento ensambla su propio contexto, delimitando un área de reterritorialización repres(entat)iva de la libertad, capitalizada por el busto de bronce elevado de un Benkos sin cadenas, sin nombre y sin palen[k]e.

El monumento es una manifestación metonímica de los procesos de monumentalización histórica que operan en Palenque. A primera vista, la escultura cristaliza una de las contradicciones constitutivas de la patrimonialización, la ambivalencia entre una imagen de Palenque como cultura aislada en medio del monte, y la flexible apertura de su construcción histórica e identitaria. En este sentido, la escultura materializa la oscilación entre la frágil inmaterialidad del patrimonio y los usos "tangibles" de su "cultura como recurso" (Yúdice). Asimismo, el espacio de la plaza concentra dos instancias paradojales de consignación de la libertad palenquera: por una parte, la iglesia y su escultura de San Basilio son índices materiales de Palenque como "primer pueblo libre de América", trazos del momento en el cual el palenque para volverse 'libre' se recodifica dentro del régimen legal español. Por otra parte, el monumento a Biojó como alegoría de la libertad cimarrona no sólo opera como epicentro de la reterritorialización del palenque como 'espacio cultural' tal y como es designado por la UNESCO, sino que da lugar a la transliteración de la libertá cimarrona en la libertad de un sujeto palenquero que emerge dentro del Estado y su fuerza de ley confirmando el dictamen hegeliano: "Freedom is nothing but the recognition and adoption of such universal and substantial objects as Right and Law, and the production of a reality that is accordant with them -the State" (Philosophy 59).

Sin embargo, siguiendo el trazo de Derrida en su cometido diferir de la metafísica hegeliana, vemos que la différance antimonumental que se marca en y con la borradura de la [k] cimarrona amenaza la substanciación oficial y la apropiación de la libertad por su monumento: "There is no essence of différance; it (is) that which not only could never be appropriated in the as such of its name or its appearing, but also that which threatens the authority of the as such in general, of the presence of the thing itself and its essence" ("Différance" 25-26). Es el intervalo que se abre con la borradura del nombre fundacional el que difiere irremediablemente la llegada y concretización del nombre propio del palenque. En este trazo que aparece y desaparece vemos lo que excede e imposibilita al monumento ¿Cómo no entender las continuadas "renovaciones"

$111 \frac{\text { Revista Iberoamericana, Vol. LXXXII, Núms. 255-256, Abril-Septiembre 2016, 597-618 }}{\text { ISSSN 2154-4794 (Electrónico) }}$ 
"reparaciones" del monumento sino como efectos de una reescritura arcóntica que busca limitar, conservar, consignar la archi-escritura antimonumental de la différance? ¿Cómo ignorar la destrucción del archivo que con éstos acaece?

\section{A MODO DE CONCLUSIÓN}

Esta recopilación sucinta del proceso de instalación, corrección y modificación de la materialidad escultórica del monumento de Benkos Biojó exhibe las suturas, desfases y pliegues trazados por el movimiento de consignación arcóntica de San Basilio de Palenque en lo monumental-nacional. El monumento es un sitio en el que una pulsión de significación histórica y política busca consolidar su presencia, alimentando, a su vez, el desplazamiento continuo de la différance que excede su voluntad de instalación. El ensayo interroga el proceso por el cual el Estado-Nación colombiano consigna a Palenque en la constitución arcóntica de su patrimonio, así como las coordenadas nomotéticas y epistemológicas en las que inscribe y denomina a esta comunidad negra del Municipio de Mahates como "El primer pueblo libre de América". Analizar la escultura de Benkos Biojó por fuera de la lógica celebratoria del reconocimiento, nos permite pensar en términos de operaciones de archivo: en las determinaciones que éste impone sobre la estructura y contenido de lo archivable, en la relación que el archivo establece con el futuro, y en las formas sutiles en que se consume a sí mismo.

Los epítetos "África en América" y "Primer pueblo libre de América" arrastran los restos (remains) de la esclavitud y el tráfico negrero y los depositan en el surgimiento de la libertad palenquera bajo una mirada esencialista que se extiende desde la identificación de "huellas culturales" hasta la consignación de la 'libertad' como la esencia palenquera. La mirada esencialista de África como la semilla de la libertad en América y de Palenque como su primera germinación, es una mirada compensatoria que sitúa a Palenque libre como la superación de la esclavitud (Aufhebung), Palenque como punto culmine de la lucha libertaria, palenque como monumento y por lo tanto como tumba de la libertad.

Propongo desarmar el a priori de la libertad como una esencia palenquera, identificable, reproducible, (conmemorable) y abrir el monumento al movimiento desmonumentalizador, a los trazos de un cimarronaje no-conveniente a los fines del Estado y su historia. Quizás esto ya está operando en los substratos de la monumentalización de Palenque, de su lengua y su cateyano. Porque es la lengua palenquera la que obsesiona, en su singularidad, en su dinamismo y arcaísmo (arkhē). La lengua cimarrona de Palenque es una historia otra de Colombia. Una historia no escrita que desafía la escritura fonética, invadiéndola de silencios no-asimilables y excediendo los registros de la historia entendida como totalidad y monumentalidad. Quizás, de manera provisoria, podamos llamar a este exceso "libertad". 


\section{Trabajos Citados}

Cunin, Elisabeth. Identidades a flor de piel. Lo 'negro'entre apariencias y pertenencias: mestizaje y categorías raciales en Cartagena (Colombia) Bogotá: IFEA-ICANH, 2003.

De Friedemann, Nina. "Vida y muerte en el Caribe afrocolombiano: cielo, tierra, cantos y tambores". America Negra 8 (1994): 83-96.

y Richard Cross. Ma Ngombe: guerreros y ganaderos en Palenque. Bogotá: Carlos Valencia Editores, 1979.

Derrida, Jacques. Mal de archivo. Una impresión freudiana. Paco Vidarte, trad.Madrid: Editorial Trotta, 1997.

"Archive Fever: A Freudian Impression". Diacritics 25/2 (1995): 9-63.

"Différance." Margins of Philosophy. A. Bass, trad. Chicago: The U of Chicago P, 1982.

Heidegger: Le question de l'être et le histoire. Cours de FENS-Ulm 1964-1965. Thomas Dutoit, ed. Paris: Éditions Galilée, 2013.

Documenta, Benkos Bioho. Monumento a la libertad en Palenque de San Basilio, Colombia.

Escalante, Aquiles. "Notas sobre el palenque de San Basilio, una comunidad negra en Colombia". Divulgaciones Etnol'Ogicas 3/5 (1954): 207-351.

Ferrari, Ludmila. "Palenque un performance de la libertad" Palenque Colombia. Oralidad, identidad y resistencia. Maglia Graciela y Armín Schwegler, eds. Bogotá: Editorial Javeriana, 2012.

Hegel, Georg Wilhelm Friedrich. Lectures On the Philosophy of World History. Introduction: Reason In History. Johannes Hoffmeister, trad. Cambridge: Cambridge UP, 1975.

Kirshenblatt-Gimblett, Barbara. "Intangible Heritage as Metacultural Production." Museum International 56/1-2 (2004): 52-64.

“Theorizing Heritage.” Ethnomusicology 39/3 (1995): 367-80.

Mantilla, Caterina. "Historias locales, historias de resistencia: Una aproximación a la cultura material de San Basilio de Palenque, siglos XVIII-XX". Memorias 4/7 (2007): 76-92.

Moñino, Yves. "Dos lenguas para hablar del mundo: San Basilio de Palenque a la hora de la globalización". 2014. MS.

Museo Nacional de Colombia. "Comunicado: Del monumento al pensamiento. Patrimonio de Colombia para la humanidad”. Catálogo. Bogotá. Octubre, 2012Enero, 2013.

Navarrete, Cristina. Cimarrones y Palenques en el Siglo XVII. Cali: Universidad del Valle, 2003. 
San Basilio de Palenque: memoria y tradición. Surgimiento y avatares de las gestas cimarronas en el Caribe colombiano. Cali: Universidad del Valle, 2008.

Schwegler, Armin. "Palenque(ro): The Search for its African Substrate". Creoles, Their Substrates and Language Typology. Clarise Lefebrve, ed. Amsterdam: John Benjamins, 2011. 225-249.

"Sobre el origen africano de la lengua criolla de Palenque(Colombia)". Palenque Colombia. Oralidad, Identidad y Resistencia. Graciela Maglia y Armin Schwegler, eds. Bogotá: Editorial Javeriana, 2012.

Smith, Laurajane y Natsuko Akagawa, eds. "Introduction." Intengible Heritage (Key Issues in Cultural Heritage). New York: Routledge, 1996. 112-127.

Spivak, Gayatry. "Can the Subaltern Speak?" Can the Subaltern Speak? Reflections on the History of an Idea. Rosalind C. Morris, ed. New York: Columbia UP, 2010.

Yúdice, George. El recurso de la cultura: usos de la cultura en la era global. Barcelona: Gedisa, 2000.

\section{Recursos Web}

UNESCO Intangible Heritage. Web <www.unesco.org/culture/ich/index>.

UNESCO. "La ruta del esclavo". n.d. Web 20 oct. 2014.

"Del monumento al pensamiento". museonacional. n.d. Web. 15 Jan 2015.

"Velorios y santos vivos". museonacional. n.d. Web. 22 Sep 2012

"Bicentenario: memoria revelada". Senalcolombia. 11 Mar 2010. Web. 15. Jan 2015. “Teatro Azul, Almas Unidas en Magia de Colores”. Crónica del Quindío. 16 sept. 2009. $<$ http://www.cronicadelquindio.com/noticia-completa-titulo-teatro_azul_almas_ unidas_en_magia_de_colores-seccion-la_cuidad-nota-3707>. 